\title{
E. T. Bell and Mathematics at Caltech between the Wars
}

Judith R. Goodstein and Donald Babbitt

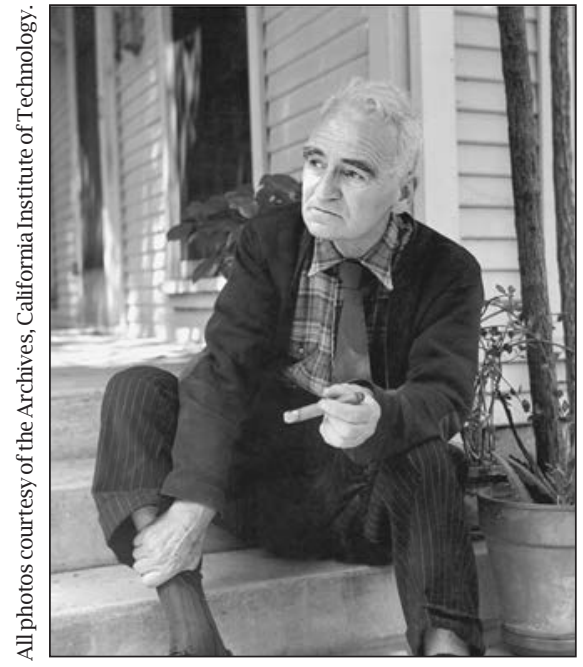

Eric Temple Bell (1883-1960), ca.
E. T. (Eric Temple) Bell, number theorist, science fiction novelist (as John Taine), and a man of strong opinions about many things, joined the faculty of the California Institute of Technology in the fall of 1926 as a professor of mathematics. At forty-three, "he [had] become a very hot commodity in mathematics" [Rei 01], having spent fourteen years on the faculty of the University of Washington, along with prestigious teaching stints at Harvard and the University of Chicago. Two years before his arrival in Pasadena he had received the American Mathematical Society's coveted Bôcher Memorial Prize for outstanding work appearing in the Society's Transactions. ${ }^{1}$ His swift election to the National Academy of Sciences was expected.

Bell had been lured to Pasadena by the renowned experimental physicist Robert A. Millikan,

Judith R. Goodstein is university archivist emeritus at the California Institute of Technology. Her email address is jrg@ca7tech.edu.

Donald Babbitt is professor of mathematics emeritus at the University of California, Los Angeles. His email address is babbitt@math.ucla.edu.

${ }^{1}$ The theory Bell advanced in his long and fundamental memoir ("Arithmetical Paraphrases", I and II) provided many applications to the theory of numbers. (Co-winner Solomon Lefschetz's paper offered essentially a complete topological theory of algebraic surfaces.)

DOI: http://dx.doi.org/10.1090/noti1009 who was in the act of transforming what had been a modest technical school into one of the country's foremost scientific institutes. It had started out in 1891 as Throop University (later, Throop Polytechnic Institute), named for its founder, philanthropist Amos G. Throop. At the end of World War I, Throop underwent a radical transformation, and by 1921 it had a new name, a handsome endowment, and, under Millikan, a new educational philosophy [Goo 91].

Catalog descriptions of Caltech's program of advanced study and research in pure mathematics in the 1920s were intended to interest "students specializing in mathematics...to devote some of their attention to the modern applications of mathematics" and promised "to provide definitely for such a liaison between pure and applied mathematics by the addition of instructors whose training and interests have been in both fields [CIT 28]". Indeed, the mathematical physics faculty at Caltech at that time was probably as good as anywhere in the country. Even if he did not write the catalog copy himself, Millikan saw the application of mathematics to other fields as a major consideration from the very beginning of his decision to expand mathematics at Caltech.

Before Bell's arrival the mathematics faculty consisted of William Birchby, Harry Van Buskirk, Luther Wear, and Harry Bateman, all holdovers from the Throop era. Birchby and Van Buskirk taught elementary courses; they were primarily mathematics teachers rather than researchers. Although he had earned a Ph.D. in mathematics from Johns Hopkins University, Wear, who handled some of the more advanced courses, did no research. Bateman, an English mathematical physicist, was the only member with sterling academic credentials. Following his graduation from Cambridge University (B.A. in 1903; Smith Prize, 1905; and M.A. in 1906), Bateman had studied 
at Göttingen and in Paris. He later taught at the University of Liverpool and the University of Manchester before immigrating in 1910 to the United States. Like Wear, he had a Hopkins doctorate (1913).

Throop Polytechnic Institute hired Bateman in 1917 as a professor of aeronautical research and mathematical physics. By then he had already compiled an impressive record as a mathematician: some seventy scientific papers on topics ranging from geometry to earthquake waves, a British Association report on the history and theory of integral equations, a Cambridge University monograph on Maxwell's equations, and a textbook in press on differential equations. ${ }^{2}$ To make ends meet, he lectured at the Bureau of Standards and reviewed papers for the Weather Bureau. At Throop, Bateman was given a free hand to develop the theoretical side of aeronautics, to suggest experimental work in a small wind tunnel under construction on campus, and to offer some advanced courses. He taught the first courses in aerodynamics and related subjects at the institute, including propeller theories, aerology, and elasticity [Gre-Goo 84]. ${ }^{3}$ Bateman's forte was not the kind of "applied mathematics" that the Hungarian-born engineer Theodore von Kármán, the first director of Caltech's Guggenheim Aeronautical Laboratory, later brought to bear so successfully on the problems of the aircraft industry. The theoretical physicist Paul Ehrenfest, writing to his wife from Pasadena in 1924, marveled at Bateman's uncanny mathematical ability but was not persuaded that the mathematician grasped the physics underlying his calculations. Ehrenfest describes a discussion he had with Bateman about some of his papers in mathematical physics as follows: "After a few questions over a half hour I could hardly see what he did or did not accomplish. He is a very pleasant fellow ... can calculate wonderfully, i.e., he has 'calculational intuition', but jumps around helplessly in the volcano of his calculations, he has no physical intuition" [Ehr 24].

Millikan had apparently given Bell some indication that he might build up pure mathematics

\footnotetext{
${ }^{2}$ Cambridge University also published Bateman's monumental tome Partial Differential Equations of Mathematical Physics in 1932, which is still available as a print-ondemand paperback.

${ }^{3}$ In addition to various topics in analysis, Bateman did research in "classical" areas of physics (electrodynamics, relativity, and hydrodynamics) and taught vector analysis, potential theory, transcendental functions, hydrodynamics, and integral equations - the sorts of things that every young classical theorist of his generation was expected to know. Between 1918 and 1928 most of his publications dealt with electromagnetic theory, which later prompted MIT mathematical physicist and polymath Edwin Bidwell Wilson to call him "probably the most powerful and consistent mathematician now working in this field" [Wil 27].
}

at the institute now that matrices had come into fashion in physics, thanks to the recent invention of matrix mechanics as a way to formulate quantum theory. But Bell came to understand even before setting foot on the campus that Millikan's "conversion" was something of a delusion. As he told Aristotle Michal, a job-hunting postdoc in mathematics whom he had met at Harvard, "Our first job will be to convert Millikan to pure mathematics-he thinks he is already

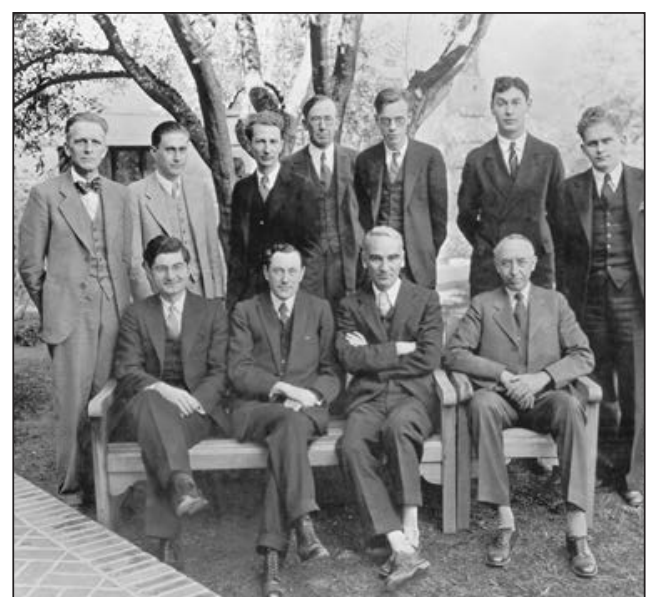

Caltech mathematics faculty and teaching fellows, 1932. Front row, from left: Aristotle Michal, Harry Bateman, Eric T. Bell, and Harry C. Van Buskirk. Rear row: William Birchby, James $\mathrm{H}$. Wayland, Carlton C. Worth, Luther E. Wear, Robert S. Martin, [unknown], and J. Lawrence Botsford. converted, but he hasn't passed the half of his salvation" [Bel 26a]. In a letter to Harvard mathematician George Birkhoff, he noted that the institute's stars were the theoretical physicist Paul Epstein, an expert on quantum theory; the "inexhaustible" Harry Bateman, who wore many scientific hats; and Richard Chace Tolman, who was "a mathematician gone wrong on chemistry" [Bel 26b].

In short, Bell was well aware of the lesser status of pure mathematics at Caltech, but he had hopes of turning Millikan around. "To my way of thinking," he told Michal, "Pasadena has the most interesting possibilities of anyplace in the United States" [Bel 26b]. In the same letter, Bell spoke of the institute's need "to build up the library and, by prevailing on Millikan to take on a few good young men, to make the place as strong in mathematics (pure) as it is in applied." Millikan, according to Bell, had given him a free hand "to work out my own problems," with the understanding that Bell was to "help with the math. physics," a task Bell thought more suitable for H. P. Robertson, who had been his student at the University of Washington.

Bell had reasons for optimism. Pure mathematics had blossomed into an active and expanding discipline in the United States in the decade following the end of World War I. In 1926 his own publishing record, which had begun at Washington in 1915, ran to sixty-eight titles, a substantial number for a ten-year period (and just a fraction of his career total of more than three hundred, not counting his fictional output as John Taine). It was a number probably matched only by Leonard Dickson, who specialized in algebra and number theory at Chicago. Nevertheless, before hiring Bell, Millikan had polled Dickson, Birkhoff, and 


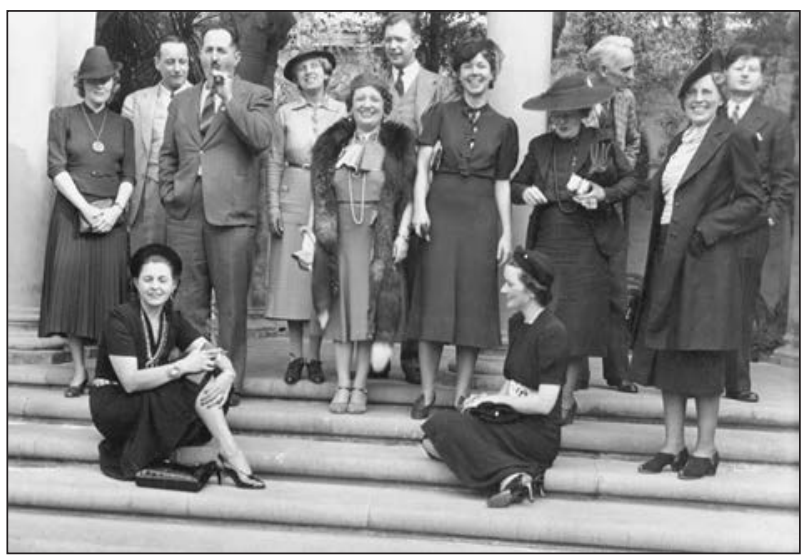

A gathering of H. P. Robertson's friends on the steps of the Athenaeum, 1936. Standing, from left: Virginia Thomas, Tracy Thomas, Howard

Percy Robertson, Ethel Bateman, Pipo von Kármán, Angus Taylor, Patsy Taylor, Toby Bell, Eric Temple Bell, Mary Bowen, and Aristotle Michal. Seated, from left: Hazel Mewborn and Luddye Michal .

Princeton's Oswald Veblen-research-minded mathematicians who had put the University of Chicago, Harvard, and Princeton on the map as outstanding centers in mathematics. More important from Millikan's point of view, all three were members in good standing of the National Academy of Sciences. As Millikan wrote to Veblen in late December 1924, "From the standpoint of physics and mathematical physics we are fairly competent here at the Institute to form judgments in which we have some confidence, but from the standpoint of mathematics I feel keenly my own incompetence" [Rei 93]. From the start, Millikan had insisted on inviting only scientists of National Academy caliber to join him in Pasadena, which helps explain why the recently anointed Nobel Prize winner asked his fellow academicians what Bell's chances were of election to the National Academy.

Veblen volunteered only that Dickson thought highly of Bell's work. Birkhoff, winner of the first Bôcher Prize, gave Bell high marks for his specialty ("[H]e is great in his field, theory of numbers") and his publishing record ("very prolific") but questioned whether Bell's long list of papers told the whole story ("[W]hen it comes to papers outside his specialty, his work is not always of high order") [Bir 25]. Dickson, however, lavished praise on Bell, describing him as "an Al mathematician of very exceptional ability in research of high order on fundamental subjects...I have long been strongly impressed by his unusual originality and his success in research of fundamental character" [Dic 25]. He predicted that Bell would be elected to the academy before Bateman was, which proved correct: Bell would be elected in 1927; Bateman's election followed in 1930, two years after he became a fellow of the Royal Society of London. If
Millikan wanted to hire Bell, added Dickson, "You could hardly...get a better man," and he cautioned that Chicago also had its eye on Bell. Nor would the Seattle mathematician likely leave the Pacific Northwest without an annual salary of $\$ 5,000$ or better, a figure the famously penny-pinching Millikan stored away for future reference.

As Dickson noted, Bell did not lack for academic suitors. Flush with sharing the Bôcher Prize, he spent the summer of 1925 lecturing on his own material at the University of Chicago and the fall semester at Harvard. He also had offers of professorships from the University of Michigan, Bryn Mawr, and Columbia University in his pocket, while Chicago began to woo him. Millikan, in discussing the need for expansion of Caltech's mathematics faculty before his Executive Council in early 1926, concluded that everything short of kidnapping should be done to acquire Bell. Bell, in turn, used Columbia's tantalizing offer of $\$ 7,500$ to secure a quick response from Millikan. Within a month, he and Millikan had reached an agreement for an annual salary of $\$ 6,000$.

\section{Mathematics on the West Coast}

Bell accepted Millikan's invitation to come to Caltech because the institute had already acquired a certain cachet in scientific circles and, perhaps just as important, because it was situated on the West Coast. A graduate of Stanford University in mathematics in 1904, Bell had earned a master's degree in mathematics from the University of Washington in 1908. He took his Ph.D. (1912) at Columbia University but signed up to teach in the Pacific Northwest even before he had turned in his dissertation. He liked to say that the West Coast, while underdeveloped, had the potential to equal anything the East Coast establishment had to offer. Bell chose Caltech over other institutions in part to prove his point. He railed against the stuffy traditions at schools such as Harvard; indeed, he would later warn at least one younger colleague that "the Eastern places" were "not the whole cheese," adding that even Washington was "better than some potty Eastern college" [Bel 26c]. In the West, one could at least breathe fresh air.

Bell's championing of the Far West mirrors the regional factionalism that accompanied the growth of mathematics in America. His instincts proved sound: during the 1920s and 1930s mathematics on the West Coast began coming into its own. In 1924 E. R. Hedrick, the first president of the Mathematical Association of America (an organization itself born of regional factionalism), left the University of Missouri to become chairman of the mathematics department at UCLA, then a brand new school in Southern California. An able administrator, Hedrick worked considerable improvements in mathematics during his tenure. The thirties saw the arrival at UCLA of refugee 
Max Zorn, followed by Angus Ellis Taylor and Tracy Thomas, who was Veblen's best differential geometry student at Princeton. The rise of mathematics at UC Berkeley is an even greater success story. In 1934 Griffith C. Evans, who had built up mathematics at Rice University in Texas, took over the chair of Berkeley's department. With Evans at the helm, it became a department rivaling those of Harvard, Chicago, and Princeton. Evans added a number of mathematicians of the first rank, including the Polish-American mathematical statistician Jerzy Neyman. Similarly, Stanford's mathematics department took off in the 1930s with the arrival of Hungarian refugees Gábor Szegö and George Pólya.

Unlike most American institutions of higher learning, Caltech lacked traditional departments and department chairs. Bell became a member of the Physics, Mathematics, and Electrical Engineering Division, which reported to Millikan. Bell would be responsible for the graduate work in mathematics, and the mathematicians looked to him to speak up for the field and take the lead in dealing with Millikan. Bell's plans to build up mathematics in Pasadena included both Robertson (who would shortly cap off a two-year fellowship in Germany with a fellowship year at Princeton) and Michal, a specialist in Fredholm and Volterra integral transformations and their FréchetGâteaux-Volterra generalized differentials. "I shall first try for Robertson (Millikan wants him), and then for you," he told Michal. "You and he will not conflict; he is primarily an applied mathematician" [Bel 26b]. Bell planned to "ditch" (his word) on Robertson the task of teaching the applied side of mathematics. "I have so many things I really want to do that I can't take time to be expert in math. physics," he wrote to Robertson, just before leaving Seattle. "For instance, I have recently opened up a whole new field in 'General Arith.' where there are hundreds of things to be done, and where the job can be best executed by one man working with a lot of able students" [Bel 26c]. Michal would sign on in 1929, but it took almost two more decades to snare Robertson.

The story of mathematics at Caltech in the interwar years is marked by a tangle of personalities and rivalries among Bell's small group of mathematicians. Relations between Michal and Bell would eventually degenerate into name-calling and shouting. ${ }^{4}$ Michal also seemed to be getting the most graduate students, which upset Bell.

\footnotetext{
${ }^{4}$ One of Michal's main goals in the thirties was to generalize the analysis and geometry on finite-dimensional manifolds to abstract infinite-dimensional manifolds, although he does not seem to have proved any new deep theorems. Other mathematicians at the time, including Bell, viewed it as abstraction for its own sake, with no sense of problem. Subsequently, however, these topics became important and active fields in pure and applied mathematics.
}

Above all, there was Bell's tumultuous love/hate relationship with H. P. (Bob) Robertson. Berkeley mathematician Abraham Haskel Taub, a longtime friend and colleague of Robertson's, analyzed it this way: "Bell and Bob were both strong people. Bell taught Bob, learned from him, fought with him in fun and sometimes not in fun, and both cared deeply for each other" [Tau 62].

\section{“A Kid Named Robertson"}

Our story begins back in 1922, when Bell, who was offering a course in mechanics at the University of Washington, encountered "a kid named H. P. Robertson" in his class who breezed through the assignments. In a letter to Harold Hotelling, a former student who later became a distinguished statistician, Bell marveled: "He was just 19 last month, and he goes through the most difficult problems and theory like a shot. Even complicated set-ups in problems by Lagrange's equations don't bother him in the least... Robertson is a prize" [Bel 22].

Bell took Robertson under his wing-much to the consternation of Washington's conservative mathematicians, who believed that research did not go hand in hand with good teaching-and got him interested in the theory of relativity. Bell taught a relativity course in the university's mathematics department, and Robertson took it in his senior year. Bell also persuaded Robertson to stay another year at Washington to continue studying mathematics, electricity, and relativity, using, for the last, Hermann Weyl's Raum-Zeit-Materie as his textbook. "If I were 15 years younger," Bell confided to Hotelling in 1922, "I would go into relativity; as it is, I hate to scrap the detailed knowledge of the theory of numbers which has taken so long to acquire" [Bel 22].

Robertson, however, followed the path of relativity and never looked back. With a bachelor's degree in 1922 and a master's in 1923 from Washington under his belt, he enrolled at Caltech for advanced graduate work in the fall of 1923 on Bell's recommendation. There were at the time at least three scientists at the institute who were interested in relativity: Tolman, especially as it applied to cosmology; Bateman, in the more technical mathematical problems; and Epstein, Caltech's sole theoretical physicist. At one of Caltech's weekly physics research conferences later that year, Robertson gave a talk on relativity in which he credited Bell with sparking his interest in the subject. Millikan and Epstein, who were in the audience, congratulated Robertson afterward on a fine talk; Robertson dodged the compliment by heaping praise on Bell. Millikan filed the name away. "Thanks for tooting my horn," Bell later wrote to Robertson. "I know what they want and they've got him-Bateman" [Bel 24]. Still, Bell appeared ready to pack his bags and head south. As he told Robertson 


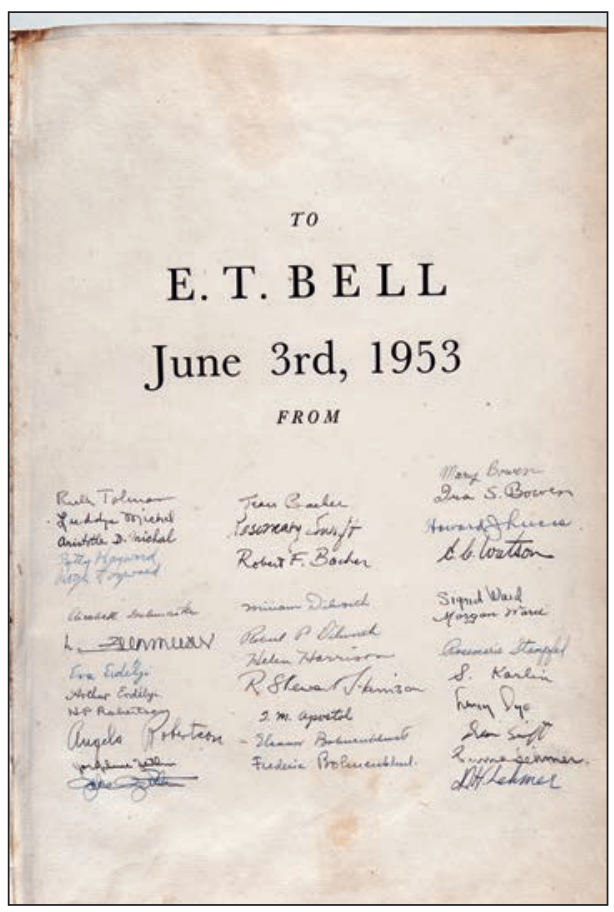

List of contributors to E. T. Bell's retirement gift in 1953. More than thirty friends and colleagues signed the flyleaf of the 1670 edition of Diophantus' Arithmetica, including Jake Zeitlin, the legendary Los Angeles rare book dealer who brokered the sale. in closing, "I'd sell my left foot to get into a job in California."

Before Bell managed to plant both feet in the Southland, Robertson had obtained a Caltech Ph.D., with a major in mathematical physics and a minor in mathematics. He learned quantum mechanics and physical hydrodynamics from visiting scientists Ehrenfest and Vilhelm Bjerknes; statistical mechanics, electricity and magnetism, and advanced dynamics from Epstein; and various other subjects under Bateman's guidance, including vector analysis, potential theory, transcendental functions, and integral equations. He completed his dissertation in 1925 on a topic in relativity, "On dynamical spacetimes which contain a conformal Euclidean 3-space", under Bateman's direction and then crossed the Atlantic for a year's study in Germany as a National Research Council Fellow in mathematics. The fellowship was renewed for a second year with the promise of a third either at Harvard or Princeton. Robertson spoke of permanently locating in Pasadena from 1928 on, "but that is as yet unsettled," he wrote in spring 1927 to a family friend [Abe 27]. "I have had suggestions from other universities looking for an assistant professor [of] mathematics or mathematical physics, and it may be to our advantage to go to one of these in spite of our preference for Pasadena." By this time, as he later recalled in a brief autobiographical sketch, "I found myself very much more interested in the physical application than in the mathematics itself" [Rob 51a].

In June 1927 Millikan wrote to Robertson, who was still in Germany and expecting to continue his N.R.C. Fellowship at Princeton, and offered him a faculty position, effective September 1928, with the status of assistant professor of mathematics on leave until that time. Robertson seemed delighted by the invitation and quickly sent back his acceptance letter. From then on, Bell began hounding his former student to publish, publish quickly, and publish often. By this time, the chemist Linus Pauling had begun to create a stir at the institute, and Bell warned Robertson that there was "one and only one way to beat him. You know what it is as well as I do" [Bel 27a].

There is no evidence to suggest that Robertson cared one way or the other about who was top dog on campus, but judging by this admonition it might have mattered to Bell, who in any case seems to have enjoyed lecturing Robertson on the need to write up his work and submit it for publication. "Millikan and the lot are watching you to see whether you can do it...for your own sake, if not God's, make good, and do it in a hurry" [Bel 28].

In the spring of 1928 Robertson asked Millikan if he could remain at Princeton for a second year. The German mathematician Hermann Weyl was set to arrive, and it seemed too good an opportunity to pass up, especially as Weyl's book on relativity theory had played an influential role in Robertson's undergraduate education. The request was granted, and soon Robertson embarked on an English translation of Weyl's celebrated book on group theory and quantum mechanics [Wey 31]. Late that fall, Caltech officials authorized Bell to open negotiations with Aristotle Michal, who had moved on to a teaching position at Ohio State University. Michal had emigrated from his native Smyrna to the United States in time to go through high school, which he followed with undergraduate work at Clark University and graduate work at Rice, culminating in a Ph.D. under Griffith Evans. Michal played hard to get, but in March of 1929four months and a flurry of letters later, mainly over how much he would be paid-he sent Bell a telegram accepting a salary of $\$ 4,500$ and an associate professorship effective September 1930. In the meantime, Robertson was expected back in Pasadena to begin teaching in the fall. Events then took an unexpected turn.

\section{The Contretemps with Robertson}

On March 20, a day after receiving Michal's telegram, Bell wrote an uncharacteristically icy letter to Robertson in Princeton-a letter totally out of keeping with the usually informal, sometimes bawdy, tone of the correspondence between the two friends - in which he intimated that Robertson might be better off teaching somewhere other than at Caltech. "This is rather an official letter, written at the request of [Millikan's assistant, Earnest] Watson and Dr. Millikan," Bell began by way of explanation. "They want to know whether you are definitely planning to return here next year... As you know, the rule here is no advancement in either rank or salary unless a man is productive. So if you see anything that you consider more attractive, please let us know as soon as possible. We must know definitely by April 1st." While "I personally hope you will accept, and fight it out on the lines 
proposed," Bell wrote in closing, he emphasized again that there was "absolutely no chance here for a man who is not productive" [Bel 29a]. On April 1 , Robertson sent Millikan a telegram saying that "under present circumstances" he felt obliged to request release from his appointment. Marietta Fay, Robertson's daughter, recalls that "both my parents were deeply hurt by Bell's letter. They never forgave him" [Rei 93].

A few days later, in a letter to Bell and Millikan, Robertson explained that he had gotten the impression that "the Institute is not satisfied with my work during the two years which have elapsed since the appointment" [Rob 29a]. On April 20, Bell replied, wondered if they were still on speaking terms, and said that he thought Robertson had "made the mistake of your life in turning down what was offered" at Caltech. As a "final parting piece of advice," he warned Robertson to "get busy, and show the world that you are doing something," all the while insisting that he took "personally the full responsibility" for the events that caused Robertson to resign [Bel 29b]. Robertson responded that there were no hard feelings but that Bell's apparent change of attitude toward him in the space of one year, and what seemed to Robertson to be the institute's view of him as an inadequate "producer", had left him no alternative but to resign, as "the only self-respecting thing to do" [Rob 29b].

Robertson's mother visited Bell and his wife, Toby, in Pasadena the following year and added her own postscript to this bizarre tale. It seemed to her, as she wrote to her son and daughter-in-law, that the Bells' admiration for her son was mixed with jealousy, stemming from the esteem in which both Richard Tolman and Princeton's mathematicians held him [A M Rob 30].

Just how "unproductive" had Robertson actually been? According to his bibliography, he published eleven papers between 1924 and 1929 on topics ranging from differential geometry and quantum theory to relativistic cosmology, including an article in 1929 in Physical Review on the uncertainty principle, which remains to this day among his most cited papers [Rob 29c]. It was not a great number, to be sure, compared with the twenty-nine papers Bell had whipped out in the first six years of his own career. Bell put a premium on showmanship, visibility, and a high profile, which is probably why he kept telling Robertson to publish his work in bits and pieces and to do it quickly rather than wait until he had pulled things together. The American mathematics community, Bell argued, likely wouldn't understand it either way. Bell continually admonished Robertson to put himself forward in every way possible-to line up offers of positions at other institutions, for example, which would impress Millikan, who "eats up this sort of thing" [Bel 28]. He seems to have feared that Robertson would end up like the diffident Bateman, whose priority in certain matters concerning special relativity, Bell believed, went unappreciated [Bel 24]. However, Robertson's intransigence suggests that he simply did not like being told what to do by other mathematicians.

After he turned Caltech down, Robertson was offered a position in Princeton's mathematics department. He refused that offer and requested instead a position like the one he had just spurned from Caltech, which would have allowed him to teach physics as well as mathematics. The university countered by offering him an assistant professorship of mathematical physics with a seat in both departments, a situation he accepted but would later vow never

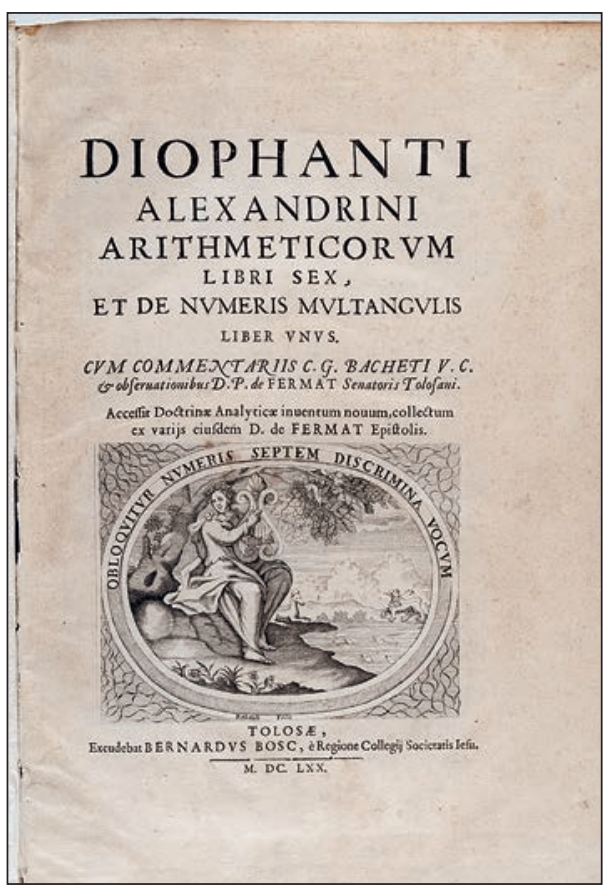

Title page of Bell's Arithmetica. The 1670 edition includes the claim made by Fermat that he had proved what Theorem but lacked space in the margin to show his work. Bell's longtime research interest in Diophantine equations set the stage for his own book about Fermat's Last Theorem, The Last Problem, published posthumously in 1961 . became known as Fermat's Last

to repeat [Rob 51a]. With the exception of a oneyear sabbatical leave in 1935-1936 (which he spent in Pasadena "at the scene of some of my former indiscretions" [Rob 35a]), Princeton remained his academic home until his permanent return to Caltech in 1947. During his tenure at Princeton, Robertson rose to prominence as one of the pivotal figures in the United States in the working out of the general theory of relativity. So when he returned to Caltech, he did so on his own terms. As he later recalled, "I had had enough of two sets of department meetings and of the intellectual arrogance of mathematicians, and elected to go into the Physics Department, although I had been offered my choice” [Rob 51a].

Bell never quit hounding his protégé to publish more often. He wrote to Oswald Veblen in the winter of 1931, "If you happen to think of it, would you mind jogging Robertson up to get out some of his stuff on mathematical physics? As it is, other people are running away with bits of it under his nose" [Bel 31a]. Even Robertson's election to the National Academy in 1951 provided Bell with ammunition. "This is something many years overdue, mainly your own fault, for straddling the fence 


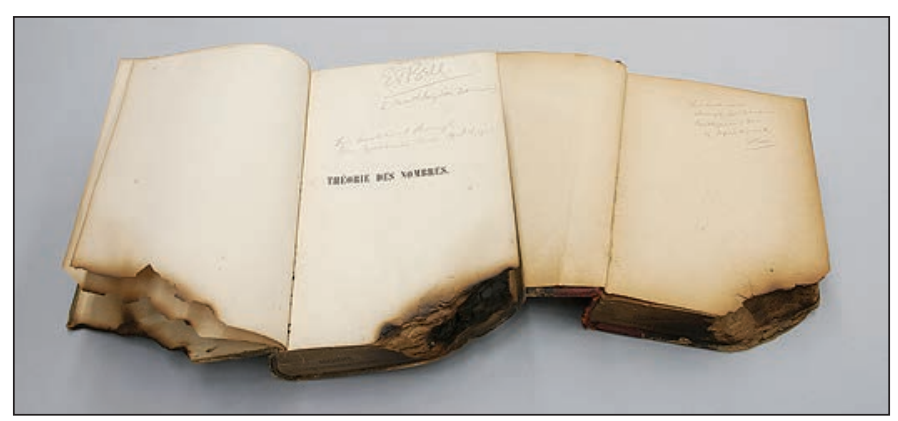

Bell was living in a boarding house in San Francisco at the time of the 1906 earthquake and buried these two math books in the backyard.

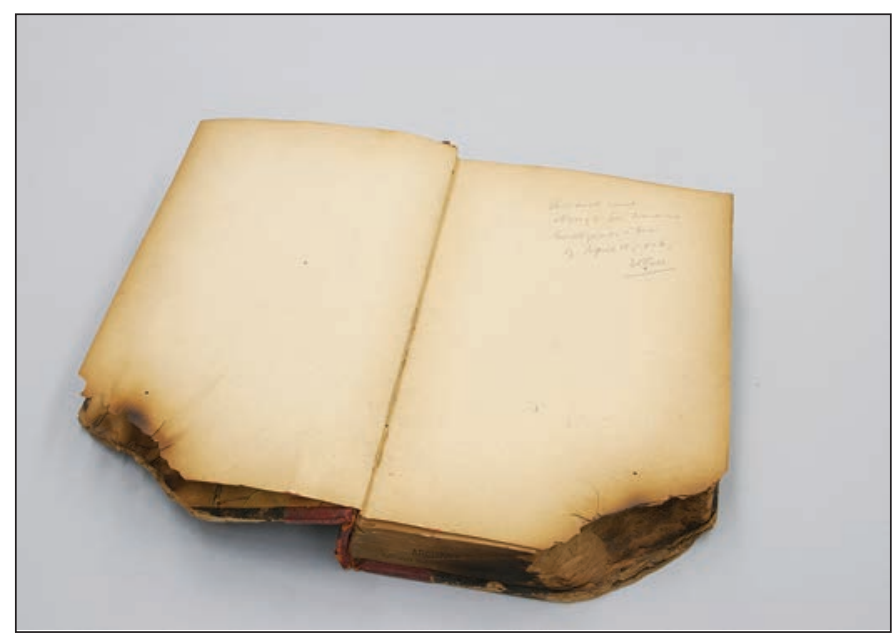

Several days later, Bell rescued his copy of Théorie des Nombres, Édouard Lucas's 1891 classic text in number theory, from the scorched earth.

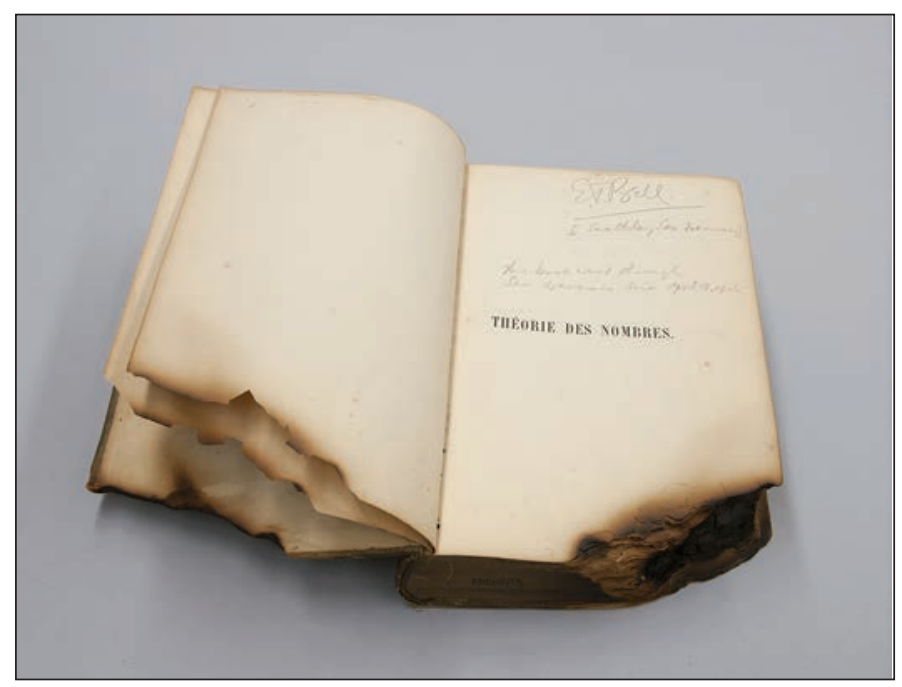

Beneath his name and the names of two cities, Seattle and San Francisco, Bell wrote the following inscription: "This book went through the San Francisco Fire April 16, 1906." Although Bell discarded most of his correspondence in later years, he kept these two charred books, which are now housed in the Caltech archives. between two sciences and not letting your fellows know on which side your balls hung," he wrote [Bel 51]. Robertson, no stranger to such repartee, replied in kind, "Thank you for your obscene congratulations...You attribute the delay in me sitting on the fence with one orchid hanging over on either side; I say they were only waiting for them to shrivel up and drop off before I would be ripe for the honor" [Rob 51b].

\section{Bringing Up the Next Generation}

Morgan Ward, Bell's first graduate student, entered Caltech in 1924 (where he was one of only forty-eight graduate students altogether) after earning his bachelor's degree at UC Berkeley. He became Caltech's first Ph.D. in mathematics, receiving his degree summa cum laude in 1928 with a dissertation on the foundations of general arithmetic; ${ }^{5}$ this was followed by his appointment as a research fellow. Like physics and chemistry at Caltech, mathematics tapped its own students from the 1920s on. In 1929 Ward joined the faculty as an assistant professor of mathematics and, aside from a year at Princeton in 1934-1935, remained at Caltech until his death in 1963. His research interests ranged from recurring series, Diophantine equations, abstract arithmetic and lattice theory ${ }^{6}$ to functional equations and numerical analysis. Like Bell, he had a deep interest in the theory of numbers and a "great contempt for those who proliferate easy empty generalizations of the great classic ideas of mathematics," according to Derrick H. Lehmer, who got to know Ward while spending the 1930-1931 academic year at Caltech on an N.R.C. Fellowship in mathematics [Leh 93].

The onset of the Great Depression in 1929 may have dampened Bell's spirits a bit. In response to a 1931 letter from Veblen hinting that he would welcome an invitation to visit Pasadena while Albert Einstein was in residence, Bell wrote:

I fear it is out of the question. The financial stringency has hit us hard. The mathematicians never did have any funds available to pay outside lecturers. The one time when we did pay a lecturer, namely Harald Bohr,

${ }^{5}$ This is how Ward viewed his thesis: "We have now
reached a logical stopping place. In Part I, we have sub-
jected the concept of a class and a binary operation to
a careful scrutiny, and shown that for the purposes of
general arithmetic, where all classes are denumerable,
we can assume the class ordered without any loss of gen-
erality, or replaced by the numbers one, two, three,...We
have thus 'arithmetized' general arithmetic in Kronecker's
sense." http://resolver. caltech.edu/ca7techETD:
etd-03042005-135853.

${ }^{6}$ Eighteen papers on these topics appeared in the Annals of Mathematics, then (and now) the leading American journal of mathematics. 
was provided for by a crumb dropped from the physicists' banquet...I was to have got a new man this year, but the money wasn't forthcoming. In the past they have usually paid railway fare to essential meetings; this year that also is cut out, so I shall have to pay my way to New Orleans. However, this depression can't last forever. [Bel 31b]

In fact, the Depression dragged on, and no new faculty appointments were made in mathematics until the early 1940s.

While at Princeton, Ward confided to Robertson that he was not entirely happy with his situation at Caltech. In a letter to H. S. Vandiver at the University of Texas, Robertson said that Ward "would welcome an opportunity for a change; this is, of course, most confidential" [Rob 35b], and on the same day he wrote to J. Robert Oppenheimer at Berkeley: "The purpose of the present note is to find out whether and to what extent you have the ear of Evans or other influential people in the Mathematics Department. Because if you have, they might be interested to know...that Morgan Ward has always had a soft spot in his heart for Berkeley...I have gotten to know Ward much better this [year] and have reason to believe he would by no means resent an opportunity for a change" [Rob 35c]. Ward in fact received a promotion and a raise at Caltech soon after his return, prompting Robertson to remark, "I suppose that makes things look different there, doesn't it? I must say it increases my respect for your Chief [Millikan]" [Rob 35d].

Angus Taylor, Aristotle Michal's first student and one of his best, was another promising star. Taylor and the other graduate students in mathematics at Caltech in the 1930s were pushed to the research frontier as quickly as possible. Because he already knew the theory of functions of a complex variable, Taylor skipped Bateman's course, which leaned heavily on Whittaker \& Watson's A Course of Modern Analysis. (He later described Bateman as "a very gentle and nice man...in a little rut all by himself" [Tay 81].) Instead, under Michal's guidance, Taylor became proficient in Lebesgue measure and integration, the theory of abstract spaces and functional analysis, and Riemannian and non-Riemannian geometry. "Michal did some lecturing, but made the students do quite a bit of it themselves," Taylor recalls [Tay 81]. He studied abstract algebra under Bell, who, he says, "didn't lecture. He had all the students tell the class what was in the books, so the students did all the lecturing; Bell commented and criticized." In a memoir for the Mathematical Association of America, Taylor characterized Bell as "a stimulating person, given to expressing strong opinions [but] I don't think he spent much time preparing what he was going to say in class" [Tay 84]. The curriculum had gaps, particularly in combinatorial topology and point-set topology, subjects offered at Princeton, Texas, Virginia, and Michigan. "There really was not a mathematics department in an administrative sense," Taylor remembered. "I don't think there was much planning of curricula. There was very little guidance of graduate students" [Tay 81].

Be that as it may, early in 1936 Veblen asked Robertson, then at Caltech on sabbatical, for his opinion of Angus Taylor. Robertson replied:

I do know Taylor fairly well, and I do think he is really very good...But the fly in the ointment is this, as you probably know by this time: Taylor has just yesterday accepted an instructorship here at the Institute, and has withdrawn his application for an N[ational] R[esearch] F[ellowship]. I am sorry he has done this just now, for I think he would profit much more at this point by contact with other schools of analysis-particularly the Johnny [von Neumann]-operatorschool! But he seems quite sure that he is doing the best thing by staying on here-and teaching brats on a twelvehour basis. [Rob 36]

Veblen refused to accept Taylor's decision and managed to persuade him to accept the fellowship from the National Research Council and come to Princeton as a postdoc, where he worked with Salomon Bochner. Taylor's fellowship was renewed for 1938-1939, and then, unexpectedly, he received an offer of appointment at UCLA for that academic year. Keen to return to California, he tried to find out whether Caltech planned to ask him back in 1939. "So there I was, in April or May of 1938, a bit up in the air about my future," he later recalled. "Then unexpectedly, I received word from E. T. Bell urging me to accept the UCLA offer. That told me what I hadn't known for sure about Caltech's interest in me. After discussing the matter with people at Princeton, and against their advice, I resigned the second year of the fellowship and took the job at UCLA. I've never regretted it" [Tay 81]. Morgan Ward, who was hoping Taylor would return to Pasadena, blamed Bell. Taylor, he wrote Robertson, would have done "his fair share of the work, something which A. D. Michal and E. T. Bell avoid successfully." Bell, he added, "seems down [on] him, but I cannot find out exactly why-he seems to have made the wrong remark to him some time ago, and Bell has treasured it" [War 38].

In 1939 Ward received an offer from Johns Hopkins and, perhaps with Taylor's fate in mind, asked Millikan "what my immediate prospects might be" [War 39]. He also took the opportunity to announce that his student Robert Dilworth, who had done his graduate work on a new algebraic theory of lattices, had just been awarded a prestigious 
Sterling Fellowship at Yale in case Millikan was thinking of hiring an assistant professor in the future. While at Yale, Dilworth continued this research, which is well documented in his book (with Peter Crawley) Algebraic Theory of Lattices, published in 1973. ${ }^{7}$ Meanwhile, Bell told Millikan that if Hopkins wanted Ward, Caltech "should do the utmost we can to make it worth his while to stay" in Pasadena [Bel 39]. Ward was promoted to professor the following year.

The first substantial revamping of Caltech's mathematics faculty in more than a decade came during the war. In 1942 a new assistant professor in mathematics was needed to replace the retiring Van Buskirk. Ward's former student Robert Dilworth and Michal's former student Angus Taylor were the candidates. The screening took place "in house". Millikan turned to several physicists at the institute for advice. They assured him that Dilworth's research was potentially of greater use to physicists, although the spectroscopist William Houston questioned the criteria Millikan appeared to be using in deciding between the two mathematicians ("I was rather surprised to have it mentioned [by you] that he [Dilworth] seemed to be more inclined toward the applications of mathematics than many other mathematicians" [Hou 42]). In a letter to one of us [JRG] many years later, Taylor wrote that he knew "that Bell and Michal were at odds over getting me to go back to Caltech from Princeton... Millikan made it quite clear, it seemed to me, that he was only interested in what Dilworth or I might be useful for in teaching the physics graduate and undergraduate students, and not at all in our scholarly potential in research" [Tay 91]. But he had no idea that he had been a candidate for a tenure-track position at the school along with Dilworth several years later. "I would not have left UCLA for Caltech then [in 1942], in any event" [Tay 81], he later reported to John Greenberg, a historian of mathematics from Pasadena.

Millikan, in his letter to Michal explaining his decision to appoint Dilworth instead of Michal's former student, assured him that "there has never been any question about the excellence of Taylor's teaching work," while advancing an argument that Michal was in no position to challenge: "Our trustees thought it undesirable to try to run the risk of creating unpleasant feeling between UCLA and the California Institute by trying to pull Taylor away from them.... and so decided to try to get Dilworth here for next fall. There is of course never anything permanent about a first appointment" [Mil 42]. Dilworth returned to Caltech as an assistant professor in 1943 and two years later was promoted

\footnotetext{
7 "He is also well known for 'Dilworth's Theorem' in combinatorics, which arose in work on posets," notes Alfred Hales, a student of Dilworth's [Hal 2012].
}

to associate professor. In the last year of the war, he served as an analyst with the 8th Air Force in Great Britain. In 1951 Dilworth would become a full professor (and a major figure in lattice theory), and while continuing his research in algebra he also worked in other fields, including probability theory and statistics.

Bell was disappointed by the turn of events. If Millikan wanted a mathematician more tuned to applied mathematics, then Robertson was the man. Others on the campus, including Ward and von Kármán, who had turned to Robertson for help on a turbulence problem during his Pasadena sabbatical, also plugged for Robertson. But Millikan, as Bell wrote to Robertson, was unwilling to "spend any real money," and Bell "frankly" saw "no chance until, if ever, Pa [Millikan] retires and a more enlightened financial policy is adopted" [Bell 42].

In 1945 Robert Millikan retired as Caltech's head, and the following year physicist Lee A. DuBridge became the institute's president. Substantial salary increases went into effect shortly after DuBridge took office. Bell's original band of mathematicians also passed into history: Harry Bateman, the AMS's Gibbs lecturer in 1943, died three years later en route to New York to receive an award from the Institute of Aeronautical Sciences. ${ }^{8}$ Aristotle Michal died of heart disease in 1953. That year, E. T. Bell retired from Caltech, twenty-seven years after coming to Pasadena. The transformation of the mathematics faculty, which Millikan had largely regarded as a service department, into a first-class research group began under the inspired leadership of H. Frederic Bohnenblust, who arrived as a full professor of mathematics in 1946. Applied mathematics as a distinct discipline came to Caltech in the mid-1960s. To avoid friction with the pure mathematicians, it was organized as a research school within Caltech's engineering division.

\section{Bell's Legacy}

Whereas Bell was a prolific writer of novels, poetry, and science fiction under his pseudonym of John Taine, he achieved true rock star recognition, or something approaching it, among mathematicians and nonmathematicians alike for Men of Mathematics [Bel 37], published in 1937. Still popular today, Men of Mathematics discusses the personalities and mathematics of a host of great mathematicians, including Niels Henrik Abel, Carl Friedrich Gauss, David Hilbert, and Bernhard

\footnotetext{
${ }^{8}$ The Bateman Manuscript Project, based in part on notes he left, started up several years later under the direction of Arthur Erdélyi and aided by three research associates, Wilhelm Magnus, Fritz Oberhettinger, and Francesco G. Tricomi, culminating in three volumes of Higher Transcendental Functions, supplemented by two volumes of Tables of Integral Transforms.
} 
Riemann, concentrating on those born from the eighteenth century on. Bell followed his account of men (and the occasional woman) in mathematics with The Development of Mathematics, issued by McGraw-Hill in 1940, with a revised edition five years later [Bel 45]. This was a sweeping account of the history of mathematics, starting with its beginnings in ancient Babylonia and Egypt and charting its progress to 1945.

Readers of The Development of Mathematics will require some mathematical sophistication to fully appreciate it. In his review in Isis, I. Bernard Cohen, the dean of American historians of science at that time, wrote, "Within one restriction, the present book is excellent; that restriction consists in the fact that it really begins on p. 99, with ch. 7: 'The Beginning of Modern Mathematics, 1637-1687.' In the first 98 pages, there are many statements that one will take exception to" [Coh 41]. Cohen's objections included Bell's breezy description of al-Khwarizmi's algebraic methods ("a psychiatrist might say it was the death instinct having its way") and "the grand manner" in which Bell demolished Plato's detractors ("Of all changes that mathematical thought has suffered in the past 2,300 years, the profoundest is the twentiethcentury conviction, apparently final, that Plato's conception of mathematics was and is fantastic nonsense of no possible value to anyone"). Like Cohen, most reviewers gave the book high praise while also calling attention to Bell's unorthodox style. D. R. Curtiss, writing in National Mathematics Magazine, noted, "After a few drier pages there is always a pungent remark on human frailties, a bit of grim humor, sometimes an aside of a half page or more on what dictators are doing to mathematics, and what philosophers or theologians would do if they could" [Cur 41]. Rudolph Langer, who reviewed the book for Science, probably spoke for many when he declared, "The presentation of the whole is admirable. It is flowing and graceful and often characterized by a genuine and delightful humour" [Lan 41].

Bell also had his detractors, some of whom accused him of being flippant. Reviewers of Men of Mathematics complained of his inclination to sacrifice historical accuracy for a more colorful story. The most blatant example is his exaggerated account of the life of Évariste Galois, who died at twenty following a celebrated duel. Did Galois really create group theory in its entirety during the last night before the duel? Not according to Tony Rothman, who in Genius and Biographers: The Fictionalization of Evariste Galois" [Rot 82] accuses Bell of inventing history. Based on his research on Galois, Rothman concludes that Bell "consciously or unconsciously saw his opportunity to create a legend ... Unfortunately, if this was Bell's intent, he succeeded." Today's historians of mathematics are even less generous in their praise of Bell as a historian. Ann Hibner Koblitz, who has written about Sonia Kovalevskaya, thinks "[Bell] might well become known to future generations of mathematicians and historians as the legend maker of the history of mathematics. It is to him that mathematicians are largely indebted for distorted impressions of their predecessors" [Joc-Efr]. Koblitz's tart remarks are echoed by Roger Cooke, who deems Bell's treatment of Kovalevskaya an "infuriatingly patronizing, innuendo-laden mistreatment" [JocEfr]. Nevertheless, E. T. Bell was undoubtedly one of America's leading mathematicians in number theory and combinatorics in the first half of the twentieth century. (For another nontechnical discussion of Bell's mathematical work, see Lincoln K. Durst's interesting Appendix to [Rei 01].) He was awarded the Bôcher Prize for his 1921 papers in the Transactions of the American Mathematical Society on arithmetical paraphrases, a notion due to Bell himself [Bel 21]. Its number theory application is to derive a huge number of identities for various arithmetic functions. An example of the principle of arithmetical paraphrase is the following: Suppose there are integers $n_{1}, a_{1}, b_{1} \ldots n_{k}, a_{k}$, $b_{k}$ such that $n_{1} \sin \left(a_{1} x+b_{1} y\right)+\cdots+n_{k} \sin \left(a_{k} x+b_{k} y\right)$ $=0$ as function of integers $x, y$. Then, for any odd function $f$ of two integral variables, we have: $n_{1} f\left(a_{1}\right.$, $\left.b_{1}\right)+\cdots+n_{k} f\left(a_{k}, b_{k}\right)=0$. If $f$ is an odd arithmetical function, then this would be an identity for this arithmetical function.

In 1926 Bell was selected to give the distinguished AMS Colloquium Lectures that led to his 1927 Colloquium publication Algebraic Arithmetic [Bel 27b]. This volume expanded on his notion of arithmetical paraphrases and Euler algebra in a very general and abstract way. Leonard Dickson, in his review in the Bulletin of the American Mathematical Society, writes:

This book of marked originality is of vital interest to advanced students in various branches of mathematics, including the theory of numbers, abstract algebra, elliptic and theta functions, Bernoullian numbers and functions and the foundation of mathematics... A leading feature of the book seems to the reviewer to be its success in a systematic attempt to find a unified theory for each of various important problems in the theory of numbers,

\footnotetext{
$\overline{{ }^{9} \text { Bell gave Tom M. Apostol, the number theorist who took }}$ Bell's place at the institute in 1950, his own personal copy of Algebraic Arithmetic, signed and dated 12 December 1927. Apostol recalls discussing the book with his student Basil Gordon "and both of us agreed that it was impenetrable" [Apo 2012]. Gian-Carlo Rota told Constance Reid that he doubted "if anyone has read it all the way through" [Rei 93]. Apostol is of the same opinion.
} 
including its interrelations with algebra and analysis. [Dic 30]

However, it seems that most mathematicians who were interested in understanding what Algebraic Arithmetic was all about had a difficult time figuring it out, especially with regard to Bell's discussion of the "umbral calculus". Dickson may well have been one of the very few people (or perhaps the only one) who understood the mathematical content of the book. ${ }^{9}$

Some of Bell's major contributions were:

Bell series [Bel 15]. These series are important arithmetic series in number theory and were so named by T. M. Apostol in [Apo 76].

Paraphrases [Bel 21], for which he won the Bôcher Prize.

Euler Algebra [Bel 23]. The Euler algebra, roughly speaking, is the formal algebra generated by the Cauchy algebra $C$ of power series in one variable and the Dirichlet algebra D of Dirichlet series. It has been an important tool in the theory of generating functions.

Algebraic Arithmetic [Bel 27b]. In this book, Bell puts his theory of paraphrases and Euler algebra into an abstract setting. Included is a heuristic and impenetrable discussion of the classical umbral calculus of Blissard. The remainder of the book is also very difficult reading. The umbral calculus was not sorted out and made rigorous until the 1970s by Gian-Carlo Rota, his students, and others. See, for example, [R, K, \& O 73].

Bell polynomials [Bel 34]. These were called exponential polynomials by Bell. Although we do not know when they were first called Bell polynomials, they were so called by John Riordan in his classic 1958 book on combinatorics [Rio 58].

Bell numbers [Bel 38]. These were called iterated exponential integers by Bell and are important in the theory of partitions (among other areas of combinatorics) [Rot 64]. They were so named in 1948 by Becker and Riordan in [B \& R 48].

\section{Appendix}

Bell's Contributions to Combinatorics by John Greenberg ${ }^{10}$

Authors' note: Bell's most significant mathematical contributions were in the field we now call combinatorics. The following description of Bell's contributions to combinatorics is the work of the late John Greenberg, who received his Ph.D. in history in 1979 from the University of Wisconsin under the direction of Daniel Siegel. This essay was to be part of his unfinished history of the Caltech mathematics department.

E. T. Bell would have been surprised to see where his real influence upon mathematics lay, at least in

\footnotetext{
${ }^{10}$ John Greenberg was a postdoc for one of us (JRG) in the
} Caltech archives for three years (1981-1984). recent times. During the Second World War, artificial intelligence came of age, alongside the invention of the digital computer. The study of networks for simulating the central nervous system helped to motivate graph theory and, in general, helped to stimulate a revival of combinatorial theory after the war. Bell's work on exponential and iterated exponential numbers, exponential polynomials, and the symbolic or "umbral" calculus was much cited in the literature on combinatorial analysis of the fifties and sixties. Chief among the mathematicians who referred to his work were Leonard Carlitz, a one-time NRC Fellow at Caltech (in 1930), and John Riordan of the Bell Laboratories, a onetime collaborator of Claude Shannon, the founder of artificial intelligence in the U.S. Bell contributed, among other things, to the development of formal power series and generating functions as tools for obtaining recurrence relations, which are important for treating combinatorial problems in a unified way. The solution of recurrence relations derived from some kind of counting problem is perhaps the most common, basic, and elementary application of generating functions in combinatorial theory [Tan 75].

Bell numbers and Bell polynomials often figure as an important feature of combinatorial and probabilistic problems. (For an example of the influence of Bell's use of generating functions in a combinatorial setting, see [Rio 57], [Rio 58].) It struck two mathematicians as odd that it took so long for the followups to what they deemed Bell's "classic paper" on exponential polynomials to appear [G \& H 62]. Rota acknowledged the widespread role that Bell's exponential numbers played in a great many problems of enumeration and of probability [Rot 64]. Thus so did the Bell polynomials manifest themselves as an important feature of many combinatorial and statistical problems [Rio 58].

Rota later tried to do what Bell failed to do in 1940, namely, put the "umbral calculus" or "symbolic calculus" on rigorous foundations. Rota's purpose was to provide even greater unity to the results of combinatorial analysis. In saying that writing the paper was like "assembling a dinosaur from a few charred bones in the desert," the author meant to pay homage to his predecessors, such as Carlitz and Riordan, not to belittle them [R, K, \& O 73]. While Bell himself did not provide ironclad foundations for his uses of formal power series and generating functions, Bell, unlike some of the authors who later cited him, also realized the difficulty, and his concerns gave rise to more than one "Bell Problem" [Gou 74].

Though Bell took note himself of "the interest in combinatorial analysis and elsewhere" of some of the objects of his attention [Bel 38], it's hard to imagine that he wouldn't have been surprised at the fact that this was the area where his greatest 
influence lay. As a historian of mathematics, Bell ridiculed the late eighteenth-century German combinatorial school, labeling it a "ridiculous interlude" [Man 75]. Bell ridiculed the German formal manipulation of binomial and multinomial coefficients and formal expansion of powers of infinite series. It seems like a strange edict for someone as well versed in the combinatorial art as Bell himself! "Bell [was an] inveterate combinatorialist and number theorist, [a] person well versed in operations with series" [Gou 74]. There is some irony that the revival of combinatorial analysis was brought about in large part by the advent of the computer and the wholesale creation of branches of mathematics to minister to computer science, for if mathematics was a science that stood on its own, as Bell seemed to think, his own work with the greatest impact was that which was pressed into the service of other sciences. If Bell abhorred the applied mathematician, he nevertheless helped to open up new areas of applied mathematics in spite of himself. Millikan, his old nemesis, would have been tickled to death! For all the clairvoyance, wit, and sagacity that ushered forth from the pen of Bell the science fiction writer, Bell the mathematician never could have foreseen or anticipated the uses to which his work would be put after his death.

\section{Acknowledgments}

We thank Alfred W. Hales and Tom M. Apostol for comments on the manuscript; Sara Lippincott for editorial support; Shelley Erwin, Loma Karklins, and Elisa Piccio in the California Institute of Technology Archives in Pasadena for assistance in locating documents, letters, and photographs; Jim Staub, in graphic resources, for photographing Bell's books; Dana Roth for bibliographic research; and the archivists at the manuscript and special collections division at the University of Washington, the Library of Congress (the Oswald Veblen papers), and the Harvard University Archives (the George Birkhoff papers) for providing manuscript material from their collections.

\section{References}

Although he wrote at length about the lives of other mathematicians, E. T. Bell glossed over many details of his own biography. Bell also systematically destroyed much of his professional correspondence before he retired. H. P. Robertson, his friend and colleague, declined to write Bell's biographical memoir for the National Academy. Constance Reid's The Search for E. T. Bell, Also Known as John Taine, published in 1993, provided the first authoritative portrait of the Scottish-born mathematician who concealed much about his family and his childhood in San Jose, CA. Reid's book, which reads like a detective story, is the starting point for anyone studying Bell. A rich source of information about Bell and mathematics at Caltech between the wars can be found in the H. P. Robertson papers, housed in the Caltech archives, which Reid consulted. However, materials were given in installments, beginning in 1971 (and processing was begun by then archivist Carol Finerman) and ending in 1998. Following the final donation in 1998, the entire collection was integrated, rearranged, and described by Dr. Erwin. We have made extensive use of these supplemental materials.

The following abbreviations are used: AM, Aristotle Michal papers; RAM, Robert Andrews Millikan papers; HPR, Howard Percy Robertson papers, all in the Institute Archives, California Institute of Technology; GB, George Birkhoff papers, Harvard University Archives; OV, Oswald Veblen papers, Library of Congress.

[Abe 27] H. P. Robertson, letter to W. H. Abel, 5 March 1927 (HPR, box 1.1).

[A M Rob 30] AnNA McLeod Robertson, letter to H. P. Robertson, 22 October 1930 (HPR, box 27.1).

[Apo 76] Tom M. ApOSTOL, Introduction to Analytic Number Theory (New York: Springer Science \& Business Media, 1976).

[Apo 2012] ___ email of 19 August 2012 to J. R. Goodstein and D. G. Babbitt.

[B \& R 48] H. W. BECKER and JOHN RIORDAN, The arithmetic of Bell and Sterling numbers, Amer. J. Math. 70: 385-394 (1948).

[Bel 15] E. T. BELL, An arithmetical theory of certain numerical functions, University of Washington Publications, Mathematical and Physical Sciences, 1: 1-44 (1915).

[Bel 21] __ Arithmetical paraphrases. I, II, Trans. Amer. Math. Soc. 22: 1-30, 198-219 (1921).

[Bel 22] ___ letter to H. Hotelling, 3 April 1922 (HPR, box 1.12).

[Bel 23] ___ Euler algebra, Trans. Amer. Math. Soc., 25: 135-154 (1923).

[Bel 24] ___ l_ letter of 8 January 1924 to H. P. Robertson (HPR, box 1.12).

[Bel 24] ___ letter of 8 January 1924 to H. P. Robertson (HPR, box 1.12).

[Bel 26a] ___ letter of 13 June 1926 to Aristotle Michal (AM, box 1.15).

[Bel 26b] __ letter to A. Michal, 21 March 1926 (AM, box 1.15).

[Bel 26c] ____ letter to A. Michal, 13 June 1926 (AM, box 1.15).

[Bel 26d] ___ letter of 15 May 1926 to A. Michal (AM, box 1.15).

[Bel 26e] ____ letter of 15 June 1926 to H. P. Robertson (HPR, box 1.12).

[Bel 27a] ___ letter of 20 October 1927 to H. P. Robertson (HPR, box 1.12).

[Bel 27b] __, Algebraic Arithmetic, AMS Colloquium Publication, 7, 1927.

[Bel 28] _— letter of 22 February 1928 to H. P. Robertson (HPR, box 1.12).

[Bel 29a] ___ letter of 20 March 1929 to H. P. Robertson (HPR, box 1.12).

[Bel 29b] __ letter of 20 April 1929 to H. P. Robertson (HPR, box 1.12). 
[Bel 31a] (OV).

[Bel 31b] , letter of 27 January 1931 to O. Veblen O. Veblen (OV).

[Bel 34] __ Exponential polynomials, Ann. Math. 35(2): 258-277 (1934).

[Bel 37] __ Men of Mathematics (New York: Simon \& Schuster, 1937).

[Bel 38] _ The iterated exponential integers, Ann. Math. 39(2): 539-557 (1938).

[Bel 39] ___ letter of 18 April 1939 to R. A. Millikan (RAM, box 24.22).

[Bel 42] ___ l_ letter of 29 August 1942 to H. P. Robertson (HPR, box 1.15).

[Bel 45] ___, The Development of Mathematics (New York: McGraw-Hill, 2d edition, 1945).

[Bel 51] ___ letter of 27 April 1951 to H. P. Robertson (HPR, box 1.15).

[Bir 25] _ l letter of 5 January 1925 to R. A. Millikan (RAM, box 25.3).

[Bir 26] ___ letter to G. Birkhoff, 25 October 1926 (GB).

[CIT 28] Bull. Calif. Inst. Technol., 37 (121): 91-92 (1928).

[Coh 41] I. Bernard Cohen, Review of The Development of Mathematics, Isis 33(2): 291-293 (1941).

[Cur 41] D. R. CuRTISs, Review of The Development of Mathematics, Nat. Math. Magazine 15(8): 435-438 (1941).

[Dic 25] L. E. Dickson, letter of 1 January 1925 to R. A. Millikan (RAM, box 25.3).

[Dic 30] L. E. Dickson, Review of Algebraic Arithmetic, Bull. Amer. Math. Soc. 36: 455-459 (1930).

[Dur 01] Appendix. Some of E. T. Bell's mathematics, in [Rei 01], 400-402.

[Ehr 24] PAUL EHRENFEST, letter of 11 January 1924 to T. Ehrenfest, quoted in C. Truesdell, An Idiot's Fugitive Essays on Science: Methods, Criticism, Training, Circumstances (New York: Springer-Verlag, 1984), 403-438.

[Goo 91] Judith R. GoodsteIn, Millikan's School: A History of the California Institute of Technology (New York: W. W. Norton, 1991).

[Gou 74] H. W. Gould, Coefficient identities for powers of Taylor and Dirichlet series, Amer. Math. Monthly 81: 3-14 (1974).

[Gre-Goo 84] J. L. GreEnBerg and J. R. Goodstein, Theodore von Kármán and applied mathematics in America, Science 222: 1300-1304 (1983).

[G \& H 62] H. W. GOULD and A. T. HARPER, Operational formulas connected with two generalizations of Hermite Polynomials, Duke Math. J. 29: 51-63 (1962).

[Hal 2012] AlFRED W. HALES, email of 26 August 2012 to D. Babbitt.

[Hou 42] William V. Houston, letter of 13 July 1942 to R. A. Millikan (RAM, box 25.1).

[Joc-Efr] JOHN J. O'CONNOR and EDMUND ROBERTSON, MacTutor History of Mathematics, http://wwwhistory.mcs.st-and.ac.uk/Biographies/Be11. htm1.

[Lan 41] RUDOLPH LANGER, Review of The Development of Mathematics, Science, New Series 93: 281-283 (1941).

[Leh 93] DERRICK H. LEHMER, The mathematical work of Morgan Ward, Mathematics of Computation 61 (203): 307-311 (1993).
[Man 75] KENNETH R. MANNING, The emergence of the Weierstrassian approach to complex analysis, Arch. Hist. Exact Sci. 14: 297-383 (1975).

[Mil 42] Robert A. MillikAn, letter of 6 July 1942 to A. D. Michal (RAM, box 25.1).

[R, K, \& O 73] G-C. ROTA, D. KAHANER, and A. ODLYZKO, On the foundations of combinatorial theory. VIII. Finite operator calculus, J. Math. Anal. Appl. 42: 684760 (1973).

[Rei 93] Letter of R. A. Millikan to O. Veblen, December 1924, quoted in Constance Reid, The Search for E. T. Bell, Also Known as John Taine (Washington, D.C. Mathematical Association of America, 1993).

[Rei 01] CONSTANCE REID, The alternative life of E. T. Bell, Amer. Math. Monthly 108 (5): 393-402 (2001).

[Rio 57] JOHN RIORDAN, The numbers of labeled colored and chromatic Trees, Acta Mathematica 97: 211-25 (1957).

[Rio 58] Introduction to Combinatorial Analysis (New York: Wiley, 1958).

[Rob 29a] H. P. Robertson, letter of 6 April 1929 to R. A. Millikan (HPR, box 4.19).

[Rob 29b] (HPR, box 1.12).

[Rob 29c] ___ The uncertainty principle, Phys. Rev. 34: 163-4 (1929).

[Rob 35a] letter to Earnest Watson, 22 April 1935 (HPR, box 6.14).

[Rob 35b] __ letter of 6 February 1935 to H. S. Vandiver (HPR, box 6.13).

[Rob 35c] ___ letter of 6 February 1935 to J. R. Oppenheimer (HPR, box 6.13).

[Rob 35d] ___ letter ca. July 1935 to M. Ward (HPR, box 6.13).

[Rob 36] _____, letter of 28 March 1936 to O. Veblen (HPR, box 1.13).

[Rob 51a] __ Further autobiographical facts, requested by the National Academy of Sciences, undated (HPR, box 27.2).

[Rob 51b] ___ letter of 18 May 1951 to E. T. Bell (HPR, box 1.15).

[Rot 64] Gian-Carlo Rota, The number of partitions of a set, Amer. Math. Monthly 71: 498-504 (1964).

[Tan 75] STEVEN M. TANNY, Generating functions and generalized alternating subsets, Amer. Math. Monthly 75: 55-65 (1964).

[Tau 62] ABRAHAM HASKel TAUB, H. P. Robertson, 19031961, SIAM Journal 10: 737-801 (1962).

[Tay 81] ANGUS ELLIS TAYLOR, letter of 2 November 1981 to J. Greenberg.

[Tay 84] ___ A life in mathematics remembered, Amer. Math. Monthly 91 (10): 605-618 (1984).

[Tay 91] ___ letter of 16 November 1991 to J. R. Goodstein.

[War 38] MORGAN WARD, letter of 20 May 1938 to H. P. Robertson (HPR, box 6.13).

[War 39] __ letter of 18 April 1939 to R. A. Millikan (RAM, box 24.22).

[Wey 31] HERMANN WEYL, The Theory of Groups and Quantum Mechanics, translated by H. P. Robertson (London: Methuen, 1931).

[Wil 27] EDWIN BIDWELl WiLson, Some recent speculations on the nature of light, Science 65: 265-271 (1927). 